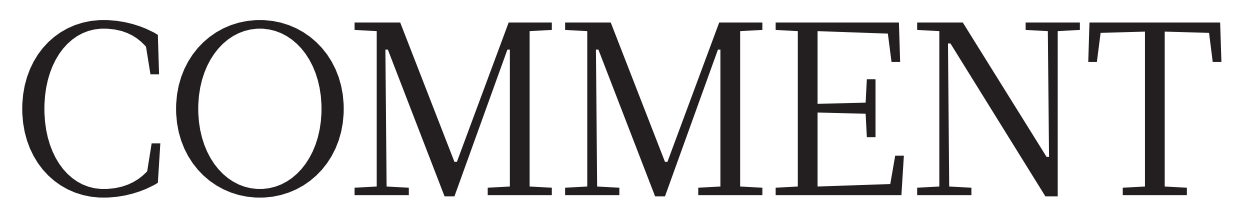

CRISPR BABIES China must $\theta$ NATURE WritING A journey

overhaul bioethics and through the wonderful inspect clinics p.184 worlds underground p.188
Music Orchestral compositions inspired by cancer, cosmology and more $\mathbf{p . 1 9 0}$
STATISTICS Lust, doubt, abuse and death - four more views on significance debate $\mathbf{p} .192$

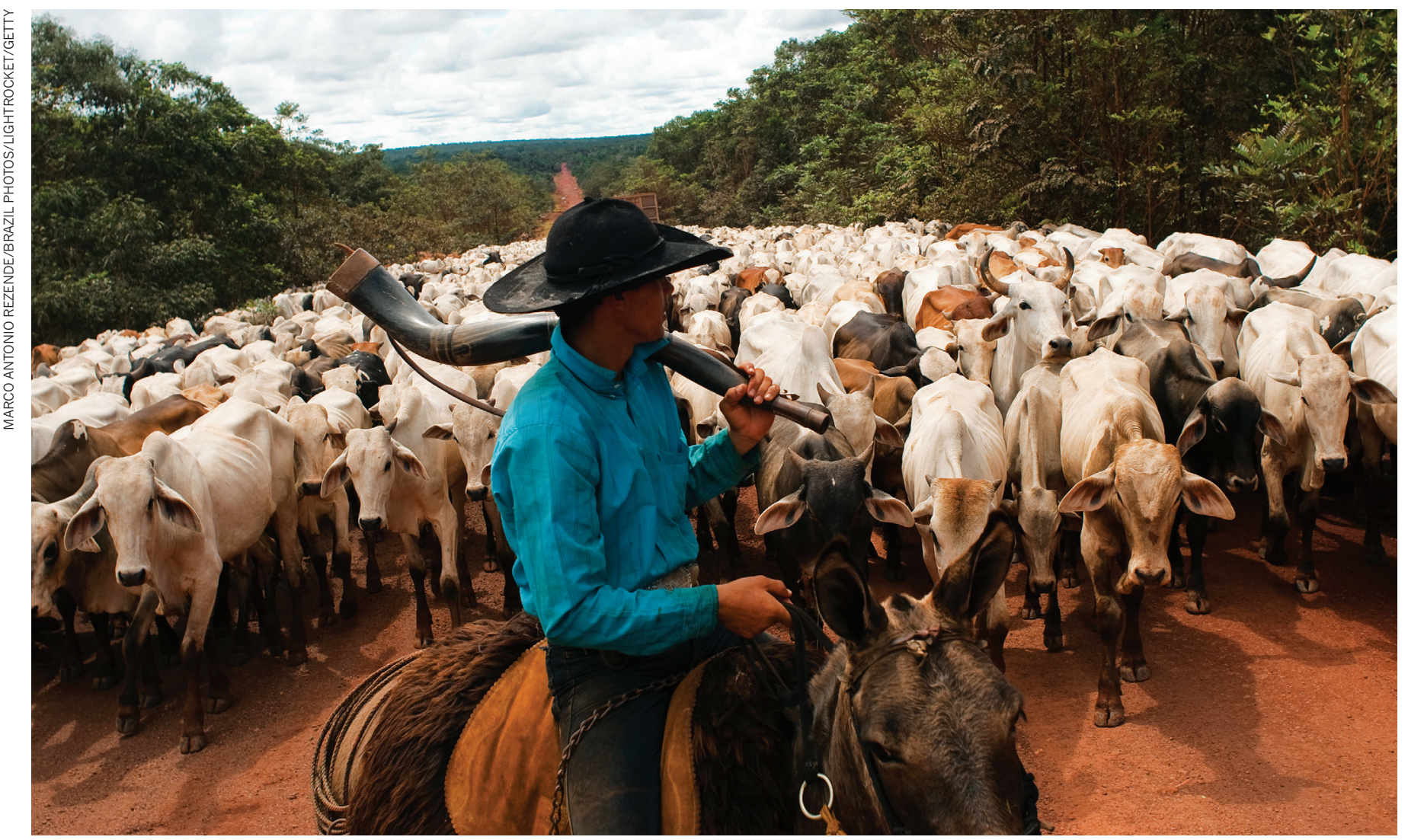

A cattle rancher in Brazil, where pressures to produce more meat collide with the need to reduce deforestation and greenhouse-gas emissions.

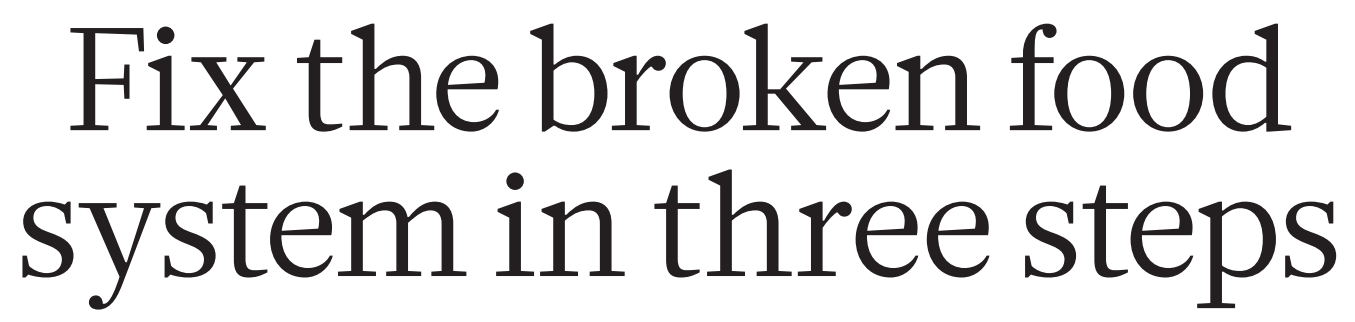

Map, model and manage agriculture, biodiversity, trade and nutrition - and build a global network, urge Guido Schmidt-Traub, Michael Obersteiner and Aline Mosnier.

$\mathrm{L}$ and use and food production are not meeting people's needs ${ }^{1}$. Agriculture destroys forests and biodiversity, squanders water and releases one-quarter of global greenhouse-gas emissions. Yet onethird of food is wasted, 800 million people remain undernourished, 2 billion are deficient in micronutrients, and obesity is on the rise. These figures will worsen as the planet warms, soils degrade and the global population grows, urbanizes and consumes more.
Threats to agriculture, climate and health are entwined. Yet policies treat each in isolation and are misaligned. National strategies for mitigating climate change pay scant attention to biodiversity and food security. The European Union's Common Agricultural Policy includes steps to reduce emissions from livestock and fertilizers, for example, but offers no way of improving diets. Ambitious targets have proved hard to attain. France has failed to halve its use of pesticides since 2008, as it proposed to do to recover biodiversity ${ }^{2}$. Brazil's strides in reducing deforestation in the 2000s are at risk of being reversed ${ }^{3}$. Meat eating is on the rise, even though it has high health and environmental costs ${ }^{1}$. Improvements in agricultural productivity are slowing.

And good intentions can have unforeseen consequences. For example, US and EU efforts to use more biofuels since 2000 have increased demand for palm oil, driving $>$ 
deforestation in tropical countries such as Indonesia ${ }^{4}$. Food systems and supply chains are prone to shocks. For instance, following a dry summer, poor harvests in Europe and the United States in 2012 drove the prices of maize (corn) and soya beans to all-time highs, triggering food riots, particularly in Africa.

What is needed are strategies for managing land-use and food systems together. These would consider links between agriculture, water, pollution, biodiversity, diets and greenhouse-gas emissions. Each sector and country can tailor solutions. But global coordination, learning and knowledge-sharing will also be necessary to ensure that the net result is sustainable and resilient, and in line with the Sustainable Development Goals (SDGs) and the 2015 Paris climate agreement.

Here we describe three steps for developing such integrated approaches.

\section{ALL TOGETHER NOW}

These steps are guided by analyses from a global network of teams of researchers from most G20 countries and nations with large agriculture and forestry sectors, such as Colombia and Ethiopia. Called the Food, Agriculture, Biodiversity, Land Use and Energy (FABLE) Pathways Consortium, it was set up in 2018 as part of the Food and Land-use Coalition by the Sustainable Development Solutions Network and the International Institute for Applied Systems Analysis in Austria (see go.nature. com/2vtpemn). We also draw on lessons from the Deep Decarbonization Pathways Project ${ }^{5}$.

Governments and researchers need to:

Agree a framework. First, agronomists, ecologists, nutritionists, climate scientists, economists and members of other technical communities must agree an overarching approach to describing the challenges of integrating land-use and food systems, and for developing solutions. The FABLE
Consortium proposes balancing three 'pillars' when managing land: efficient and resilient agriculture and fisheries; biodiversity conservation and restoration; and healthy diets (see 'Three priorities for land and food'). All are equally important and interdependent.

For example, agronomists should consider dietary requirements and biodiversity when designing strategies for providing nutritious food for all.

In many countries, this will mean growing more fruits, vegetables and legumes. Agricultural practices should minimize damage to the environment. And trade-offs between conserving biodiversity and producing food intensively must be considered.

Researchers will have to work out how to produce more food on limited land. Improvements in plant and animal genetics would increase yields. New agricultural practices that minimize environmental damage and use resources efficiently should be expanded. These include precision farming (which uses GPS and other technologies to measure and respond to variability within and between agricultural production systems), drip irrigation and integrated pest management. Robotics, sensor webs and artificial intelligence could help to increase farmers' incomes by linking markets, optimizing inputs and reducing food loss and waste ${ }^{6}$.

Governments must conserve forests, peatlands, wetlands, savannahs and coastal and marine areas to deliver crucial ecosystem services and store carbon. Similarly, food-consumption patterns need to be changed - in most countries, these are unhealthy, wasteful and harmful to the environment ${ }^{1}$. Unprecedented changes in behaviour, food-production methods and supply chains will be required to reduce

\section{THREE PRIORITIES FOR LAND AND FOOD}

Considering all three 'pillars' alongside global supply chains and other demands on land will help countries to integrate strategies for delivering healthy food, conserving biodiversity and reducing emissions.

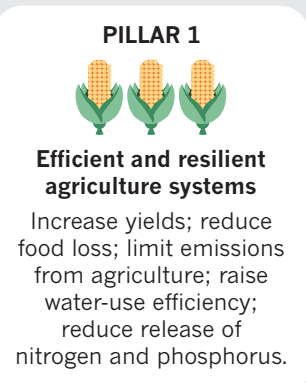

\section{PILLAR 2}

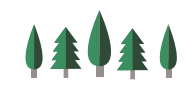

Conservation and

restoration of biodiversity

Limit emissions from deforestation; protect a minimum share of

terrestrial land; ensure

that land supports

biodiversity conservation.

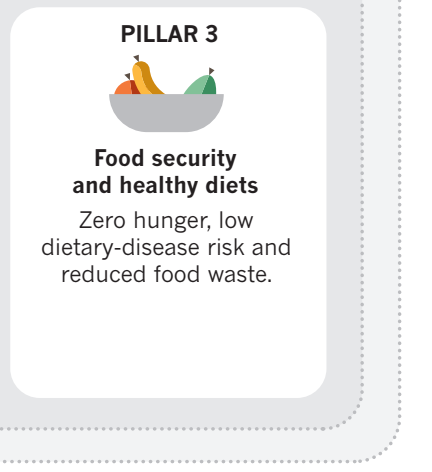

food waste at the scale required to meet the SDGs, and to alter people's diets so that they contain less processed food and meat, and more fruits, nuts, vegetables and whole grains. Although there have been isolated successes, such as bans of trans-unsaturated fatty acids in some countries, including Denmark and the United States, most interventions so far have been insufficient ${ }^{1}$.

Countries should take into account competing demands for land, including urban sprawl, industry and infrastructure development. And they should examine the impacts of international trade and global supply chains on their own resources. The aim is to find integrated strategies that are balanced across the three pillars. For example, intensifying cattle ranching in Brazil would reduce deforestation locally and internationally, while mitigating global greenhouse-gas emissions ${ }^{7}$.

Build national models. Countries need data and tools to develop coherent national policies covering all uses of land. First, governments need to collect data across the three pillars, including on land use, soil and water resources, biodiversity, carbon stocks, transport infrastructure, climate impacts, consumption patterns and food waste. International trade in agricultural products should also be included, to identify imbalances.

All of these data must be harmonized, curated and integrated. For example, India's space programme collects remote-sensing data on land use and infrastructure that could be applied in policymaking. China collects data to establish and monitor its ecological 'redlines' for agriculture, water use, biodiversity and ecosystem services ${ }^{8}$. Household survey data (on incomes or health outcomes, for example) should be combined with biophysical data on hydrology, land use and disaster risk. Poorer countries will require international support to build databases and models.

Advanced geospatial models of land, food production and trade should then be built to test policy options and develop pathways ${ }^{5}$. Only a few countries have tried, and none of the models yet includes diets. Brazil has modelled the impacts of policies that reduce emissions from deforestation. Researchers analysed agricultural production, land cover, biodiversity and transport infrastructure to project how policies might change domestic consumption and global demand for soya, sugar cane, beef, bioethanol and timber. The results informed Brazil's ambitious pledges to the Paris climate conference in 2015. Unfortunately, these are unlikely to be met by 2020 . The full suite of policies was not implemented, and the rate of deforestation has nearly doubled since 2012 (ref. 3).

Other countries use different models for planning. For example, the Australian National Outlook assesses economic activity, resource use, environmental performance 


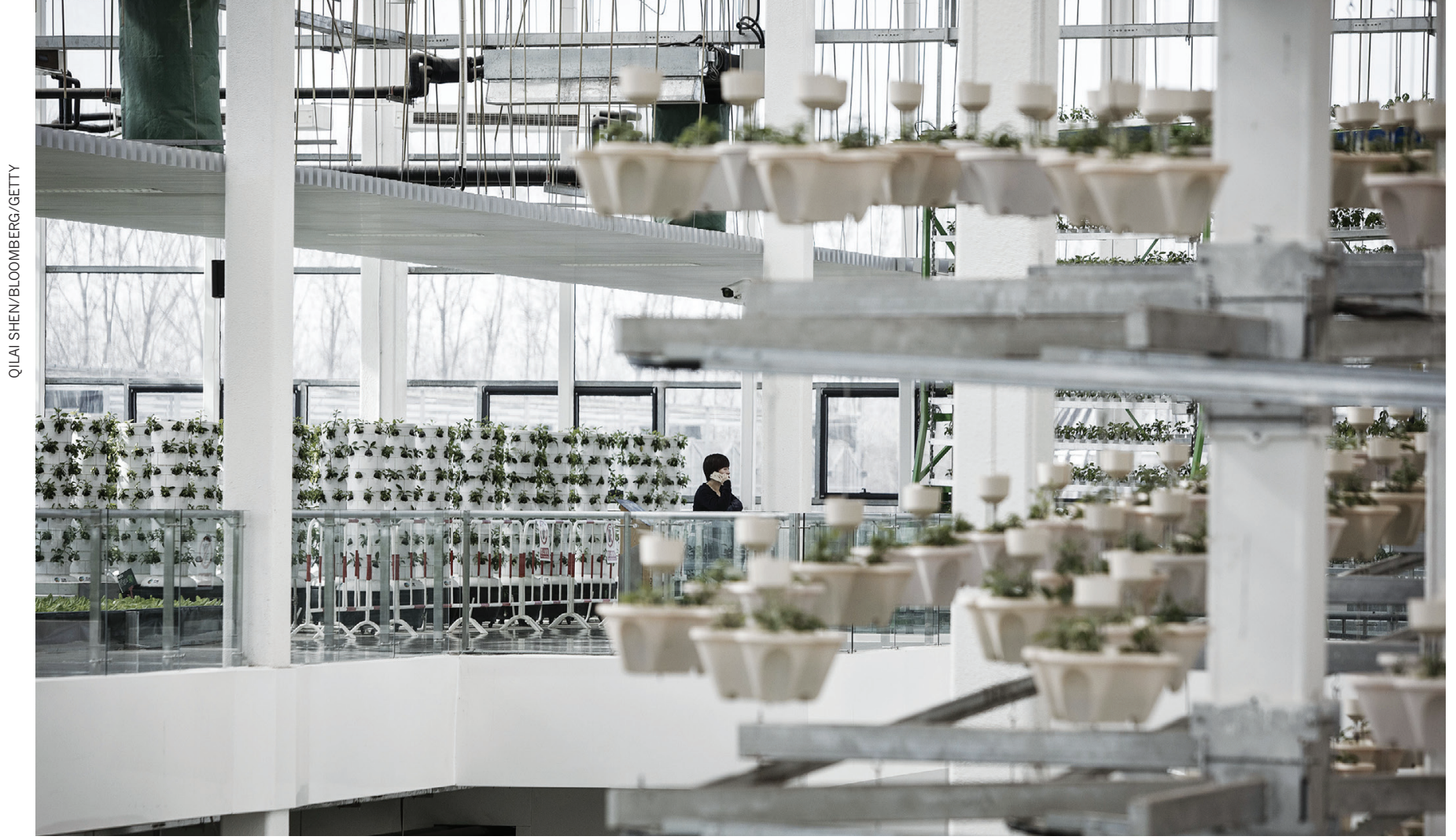

Potted plants grow in a rotary light-tracking system in a greenhouse at an indoor farm near Beijing - one way in which China is increasing land productivity.

and living standards ${ }^{9}$ to inform national policies for reducing greenhouse-gas emissions without compromising agricultural productivity. And the European Union used integrated land-use modelling with energy and economic models to inform its targets for achieving zero net emissions by 2050 (ref. 10). China has compiled data for its redlines, but it lacks models for testing the impact of policies across the three pillars and the policies' interactions with trade.

Finally, simple spreadsheet tools can identify major imbalances in and threats to national food and land-use systems without the need for complex geospatial data or optimizations. The FABLE Consortium will release one such tool later this year. These can also engage policymakers and stakeholders in identifying and addressing major challenges.

Build a global network. National efforts need to be coordinated so that they collectively meet the aims of the SDGs and Paris agreement. FABLE is acting as a hub by providing countries with training and technical support for modelling, encouraging the development of integrated policies and sharing information about effective technologies and practices.

Through an iterative process we call a 'scenathon', consortium members identify and fill gaps between global goals and the projected sum of national pathways. They identify imbalances in trade flows and suggest refinements to policies. Work so far underscores the difficulties that countries face in pursuing multiple, competing objectives. It is also challenging to translate global targets, such as "well below $2^{\circ} \mathrm{C}$ ", to the national level. Country teams often expect other nations to make deeper emissions cuts.
FABLE also organizes technology round tables, at which country teams engage with world-leading technical experts from science and business on issues from reducing the amount of methane emitted by cattle to largescale deployment of precision agriculture.

Now that the consortium is up and running, more countries need to get on board. And sustained funding needs to be found, which is difficult for work that falls between conventional areas of science and policy.

\section{WHAT NEXT?}

The year 2020 is a milestone for many multilateral processes, including the Conference of the Parties to the Convention on Biological Diversity and to the United Nations Framework Convention on Climate Change. In the run-up, governments and scientists need to perform integrated analyses.

We urge scientists, policymakers and other stakeholders to adopt the three-pillars for sustainable food and land-use systems to overcome fragmentation. Each pillar needs to be refined, and scientists need to develop medium- and long-term performance and technology benchmarks. These might be informed by approaches developed in the energy sector, as developed by the Science Based Targets Initiative, or the emerging standards for healthy diets proposed by the EAT-Lancet Commission ${ }^{1}$.

Governments should invest in national capacities for integrating data, analytics and assessments to support evidence-based policymaking, directing greater funding to data collection and modelling of food systems and land use. Training and the exchange of knowledge between countries, as supported by FABLE, can speed this up. Scientists should aim to create supporting data in transparent and reproducible ways. International mechanisms for collecting geospatial data, such as those coordinated by the Group on Earth Observations (GEO), can help to fill national data gaps. Each country will need to decide which data should be private and which should be open.

Taking these steps will allow countries to craft the long-term, low-emission development strategies required under the Paris agreement. These measures are needed to secure the food, biodiversity and ecosystem services on which we and the planet depend. .

Guido Schmidt-Traub is executive director of the Sustainable Development Solutions Network, Paris, France. Michael Obersteiner is programme director of Ecosystems Services and Management, International Institute for Applied Systems Analysis, Laxenburg, Austria. Aline

Mosnier is scientific director of FABLE, Sustainable Development Solutions Network, Paris, France.

e-mail: guido.schmidt-traub@unsdsn.org

1. Willett, W. et al. Lancet 393, 447-492 (2019).

2. Stokstad, E. Science https://doi.org/10.1126/ science.aav6762 (2018).

3. Rochedo, P. R. R. et al. Nature Clim. Change 8 695-698 (2018)

4. Valin, H. et al. The Land Use Change Impact of Biofuels Consumed in the EU: Quantification of Area and Greenhouse Gas Impacts (Ecofys, 2015)

5. Waisman, H. et al. Nature Clim. Change $\mathbf{9}$, 261-268 (2019).

6. Asseng, S. \& Asche, F. Sci. Robot. 4, eaaw1875 (2019).

7. Cohn, A. S. et al. Proc. Natl Acad. Sci. USA 111, 7236-7241 (2014).

8. Bai, Y. et al. Land Use Policy 55, 348-351 (2016).

9. Hatfield-Dodds, S. et al. Nature 527, 49-53 (2015)

10.European Commission. A Clean Planet for All: A European Long-Term Strategic Vision for a Prosperous, Modern, Competitive and Climate Neutral Economy (European Commission, 2018). 